ISSN 1991- 8690

website: http://jsci.utq.edu.iq

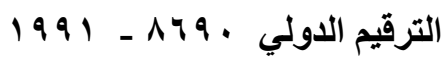

Email: utjsci@utq.edu.iq

\title{
Adomian decomposition method for solving two-dimensional Schrödinger equation
}

\author{
A.S.J. AL-Saif* \\ Department of Mathematics- College of Education- University of Basrah- \\ Basrah- IRAQ
}

\begin{abstract}
$\underline{\text { Abstract }}$
In this paper, Adomian decomposition method is applied to approximate the solution of two-dimensional Schrödinger equation. Also, the convergence proof of the Adomian decomposition method is presented. The method was compared with other methods in the aspects of convergence and accuracy. The results show that the Adomian decomposition method is more accurate, and has better convergence than the other methods in literature, and CPU times needed for this problem are reported.
\end{abstract}

Keywords: Adomian decomposition method, Schrödinger equation.

\section{Introduction}

The Schrödinger equation is a typical dispersive (linear and/or nonlinear) partial differential equation that plays a key role in a variety of areas in mathematical physics. It attracted the attention of many researchers and appeared in a wide range of applications $[6,13,14]$. Consider the initial-boundary value problem for two-dimensional time dependent Schrödinger equation (TDSE) with arbitrary potential function $\psi=\psi(x, y)$ as,

$$
\begin{array}{lcl}
i u_{t}+\nabla^{2} u+\psi u=0 & 0 \leq x, y \leq 1, t \geq 0 & \\
u(x, y, 0)=f(x, y) & 0 \leq x, y \leq 1, & \\
u(0, y, t)=g_{0}(y, t), & u(1, y, t)=g_{1}(y, t) & 0 \leq y \leq 1, t \geq 0 \\
u(x, 0, t)=h_{0}(x, t), & u(x, 1, t)=h_{1}(x, t) & 0 \leq x \leq 1, t \geq 0
\end{array}
$$

where $f, g_{0}, g_{1}, h_{0}$ and $h_{1}$ are the initial and boundary data.

\footnotetext{
Corresponding author, (ajsaif9@ hotmail.com), Ph D. in computational mathematics .
} 
This model is derived from the vector wave equation for electric field which governs the propagation of electro-magnetic waves in a homogeneous medium [7].The Adomian decomposition method has been applied to problems in several fields of mathematics, physics, biology, chemical reaction, and so on. Recently, there has been a great deal of interest in applying Adomian decomposition technique for solving a broad class of partial differential equations $[1-5,9,10]$.

In this article, the Adomian decomposition method is applied to approximation solution of the two-dimensional Schrödinger equation, with proving the convergence of this solution. High accurate results and best CPU times are obtained in comparison with Noye-Hayman implicit method (N-H IM[11,13], and Paceman-Rachford ADI method(P-R ADIM) [8,13].

The rest of this paper is organized as follows: the next section describe the Adomian decomposition method which applied to approximate the solution of two-dimensional Schrödinger equation. In section 3, the results of numerical experiment are introduced. Section 4 shows the convergence of ADM, and finally conclusions are given in the last section.

\section{Adomian decomposition method}

In this section, the Adomian decomposition method for partial differential equations is applied to solve Schrödinger equation. The decomposition method [1-3] consists of computing the solution of equation (1) as an infinite series in which each term can be easily determined by the iterative scheme

$$
\begin{aligned}
& u_{0}=f(x, y) \text { given } \\
& u_{k+1}=\sum_{k=0}^{\infty} u_{k}
\end{aligned}
$$

To illustrate, we have written equation (1) in operator forms as

$$
L_{t} u=i\left(L_{x x}+L_{y y}+\psi\right) u
$$

with notations $L_{t}=\partial_{t}, L_{x x}=\partial_{x x}$, and $L_{y y}=\partial_{y y}$. Then, the inverse operator of $L_{t}$ is defined

by the definite integral $\mathbf{L}_{\mathbf{t}}^{-1}(\cdot)=\int_{0}^{\mathbf{t}}(\cdot) \mathbf{d} \tau, \mathbf{t}>\mathbf{0}$. Now, with applying the inverse operator $L_{t}^{-1}$ to equation (6) subject to initial condition (2), it yields the formula solution to equation (1)

$$
u(x, y, t)=f(x, y)+i L_{t}^{-1}\left(L_{x x}+L_{y y}+\psi\right) u \quad, t \geq 0
$$

The Adomian decomposition method [2] assumes a solution of the series form

$$
u(x, y, t)=\sum_{k=0}^{\infty} u_{k}(x, y, t),
$$

where the components $u_{k}(x, y, t)$ are going to be determined recurrently. 
Substituting these decomposition series into (7) gives

$$
\sum_{k=0}^{\infty} u_{k}(x, y, t)=f(x, y)+i \sum_{k=0}^{\infty} L_{t}^{-1}\left(L_{x x}+L_{y y}+\psi\right) u_{k}(x, y, t)
$$

Acoording to [2] $u_{0}(x, y, 0)$ is identified with initial data $f(x, y)$ and the following recurrence is proposed

$$
\begin{gathered}
u_{0}=f(x, y) \\
u_{k+1}=i L_{t}^{-1}\left(L_{x x}+L_{y y}+\psi\right) u_{k} \\
=i \int_{0}^{t}\left(L_{x x}+L_{y y}+\psi\right) u_{k} d \tau \quad, k=0,1,2, \ldots
\end{gathered}
$$

Since in practice all (or not) terms of (8) can be calculated to approximate the solution. Finally summing up the iterates according to (9) yields $U_{M}=\sum_{k=0}^{M} u_{k}, \quad M \geq 1$

Equation (11) represents the approximate solutions resulting from employing the Adomian decomposition method. And the exact solution is $u(x, y, t)=\lim _{M \rightarrow \infty} U_{M}$.

\section{$\underline{\text { Numerical experiment and discussions }}$}

To test the ADM described above, we consider equation (1) with potential function $\psi(x, y)=1-2 \frac{\left(x^{2}+y^{2}\right)}{x^{2} y^{2}}$ and the initial condition $f(x, y)=x^{2} y^{2}$.

Using these data into (10) and (11), we obtain the following successive approximation

$$
\begin{aligned}
& U_{0}=x^{2} y^{2} \\
& U_{1}=x^{2} y^{2}+x^{2} y^{2} \cdot i t \\
& U_{2}=x^{2} y^{2}+x^{2} y^{2} \cdot i t+x^{2} y^{2} \cdot \frac{(i t)^{2}}{2 !} \\
& U_{3}=x^{2} y^{2}+x^{2} y^{2} \cdot i t+x^{2} y^{2} \cdot \frac{(i t)^{2}}{2 !}+x^{2} y^{2} \cdot \frac{(i t) 3}{3 !} \\
& \vdots \\
& U_{M}=x^{2} y^{2}\left(1+i t+\frac{(i t)^{2}}{2 !}+\frac{(i t) 3}{3 !}+\ldots\right)
\end{aligned}
$$

The ADM introduces the use of $u(x, y, t)=\lim _{M \rightarrow \infty} U_{M}$. That gives the exact solution by

$$
u(x, y, t)=x^{2} y^{2} e^{i t}
$$


The results that are obtained for ADM and analytic solution at $t=1$ are listed in tables 1,2 for real and imaginary parts of $u(x, y, t)$ respectively. It seems from the results that the ADM in convergence is faster to analytic solution with high accuracy. This fact is also illustrated in Fig(1). From these figures, we noted that when $M<4$ the number of terms needed is not enough to obtain the approximately accurate solutions. While, $M>4$ for the results are coincident with exact solution. The overall errors can be made even much smaller by adding new terms of decomposition. Moreover, the rate of convergence is increased with the increase of the total number of terms for $t=1$.

To show the efficiency of the ADM for solving Schrödinger equation, we compare it with other methods namely, N-H IM and P-R ADIM (see table 3 and figure 2) for real and imaginary parts of $u(x, y, t)$ respectively. From the results, we see that ADM is better than the other methods in accuracy, convergence, execution time (CPU), and computational workloads.

\section{Table 1. Comparison of real part for both of the exact solution and ADM results}

\begin{tabular}{|c|c|l|l|l|l|l|}
\hline$x$ & $y$ & Exact $u$ & Adomian $U_{2}$ & Adomian $U_{4}$ & Adomian $U_{8}$ & Adomian $U_{12}$ \\
\hline 0.1 & 0.1 & $\mathbf{5 . 4 0 3 0 2 \mathrm { E } - 0 5}$ & $5.00000 \mathrm{E}-05$ & $5.41667 \mathrm{E}-05$ & $5.40303 \mathrm{E}-05$ & $\mathbf{5 . 4 0 3 0 2 \mathrm { E } - 0 5}$ \\
0.2 & 0.2 & $\mathbf{8 . 6 4 4 8 4 \mathrm { E } - 0 4}$ & $8.00000 \mathrm{E}-04$ & $8.66667 \mathrm{E}-04$ & $8.64484 \mathrm{E}-04$ & $\mathbf{8 . 6 4 4 8 4 \mathrm { E } - 0 4}$ \\
0.3 & 0.3 & $\mathbf{4 . 3 7 6 4 5 \mathrm { E } - 0 3}$ & $4.05000 \mathrm{E}-03$ & $4.38750 \mathrm{E}-03$ & $4.37645 \mathrm{E}-03$ & $\mathbf{4 . 3 7 6 4 5 \mathrm { E } - 0 3}$ \\
0.4 & 0.4 & $\mathbf{1 . 3 8 3 1 7 \mathrm { E } - 0 2}$ & $1.28000 \mathrm{E}-02$ & $1.38667 \mathrm{E}-02$ & $1.38317 \mathrm{E}-02$ & $\mathbf{1 . 3 8 3 1 7 \mathrm { E } - 0 2}$ \\
0.5 & 0.5 & $\mathbf{3 . 3 7 6 8 9 \mathrm { E } - 0 2}$ & $3.12500 \mathrm{E}-02$ & $3.38542 \mathrm{E}-02$ & $3.37689 \mathrm{E}-02$ & $\mathbf{3 . 3 7 6 8 9 \mathrm { E } - 0 2}$ \\
0.6 & 0.6 & $\mathbf{7 . 0 0 2 3 2 \mathrm { E } - 0 2}$ & $6.48000 \mathrm{E}-02$ & $7.02000 \mathrm{E}-02$ & $7.00232 \mathrm{E}-02$ & $7.00232 \mathrm{E}-02$ \\
0.7 & 0.7 & $\mathbf{1 . 2 9 7 2 7 \mathrm { E } - 0 1}$ & $1.20050 \mathrm{E}-01$ & $1.30054 \mathrm{E}-01$ & $1.29727 \mathrm{E}-01$ & $\mathbf{1 . 2 9 7 2 7 \mathrm { E } - 0 1}$ \\
0.8 & 0.8 & $\mathbf{2 . 2 1 3 0 8 \mathrm { E } - 0 1}$ & $2.04800 \mathrm{E}-01$ & $2.21867 \mathrm{E}-01$ & $2.21308 \mathrm{E}-01$ & $\mathbf{2 . 2 1 3 0 8 \mathrm { E } - 0 1}$ \\
0.9 & 0.9 & $\mathbf{3 . 5 4 4 9 2 \mathrm { E } - 0 1}$ & $3.28050 \mathrm{E}-01$ & $3.55388 \mathrm{E}-01$ & $3.54493 \mathrm{E}-01$ & $\mathbf{3 . 5 4 4 9 2 \mathrm { E } - 0 1}$ \\
\hline
\end{tabular}

Table 2. Comparison of imaginary part for both of the exact solution and ADM results

\begin{tabular}{|c|l|l|l|l|l|l|}
\hline$x$ & $y$ & Exact $u$ & Adomian $U_{2}$ & Adomian $U_{4}$ & Adomian $U_{8}$ & Adomian $U_{12}$ \\
\hline 0.1 & 0.1 & $\mathbf{8 . 4 1 4 7 1 \mathrm { E } - 0 5}$ & $1.00000 \mathrm{E}-04$ & $8.33333 \mathrm{E}-05$ & $8.41468 \mathrm{E}-05$ & $8.41471 \mathrm{E}-05$ \\
0.2 & 0.2 & $1.34635 \mathrm{E}-03$ & $1.60000 \mathrm{E}-03$ & $1.33333 \mathrm{E}-03$ & $1.34635 \mathrm{E}-03$ & $1.34635 \mathrm{E}-03$ \\
0.3 & 0.3 & $6.81592 \mathrm{E}-03$ & $8.10000 \mathrm{E}-03$ & $6.75000 \mathrm{E}-03$ & $6.81589 \mathrm{E}-03$ & $6.81592 \mathrm{E}-03$ \\
0.4 & 0.4 & $2.15417 \mathrm{E}-02$ & $2.56000 \mathrm{E}-02$ & $2.13333 \mathrm{E}-02$ & $2.15416 \mathrm{E}-02$ & $\mathbf{2 . 1 5 4 1 7 \mathrm { E } - 0 2}$ \\
0.5 & 0.5 & $\mathbf{5 . 2 5 9 1 9 \mathrm { E } - 0 2}$ & $6.25000 \mathrm{E}-02$ & $5.20833 \mathrm{E}-02$ & $5.25918 \mathrm{E}-02$ & $\mathbf{5 . 2 5 9 1 9 \mathrm { E } - 0 2}$ \\
0.6 & 0.6 & $1.09055 \mathrm{E}-01$ & $1.29600 \mathrm{E}-01$ & $1.08000 \mathrm{E}-01$ & $1.09054 \mathrm{E}-01$ & $1.09055 \mathrm{E}-01$ \\
0.7 & 0.7 & $2.02037 \mathrm{E}-01$ & $2.40100 \mathrm{E}-01$ & $2.00083 \mathrm{E}-01$ & $2.02036 \mathrm{E}-01$ & $\mathbf{2 . 0 2 0 3 7 \mathrm { E } - 0 1}$ \\
0.8 & 0.8 & $\mathbf{3 . 4 4 6 6 7 \mathrm { E } - 0 1}$ & $4.09600 \mathrm{E}-01$ & $3.41333 \mathrm{E}-01$ & $3.44665 \mathrm{E}-01$ & $\mathbf{3 . 4 4 6 6 7 \mathrm { E } - 0 1}$ \\
0.9 & 0.9 & $\mathbf{5 . 5 2 0 8 9 \mathrm { E } - 0 1}$ & $6.56100 \mathrm{E}-01$ & $5.46750 \mathrm{E}-01$ & $5.52087 \mathrm{E}-01$ & $\mathbf{5 . 5 2 0 8 9 \mathrm { E } - 0 1}$ \\
\hline
\end{tabular}


Table 3. Comparison of the absolute error for ADM, N-HIM and P-RADIM

\begin{tabular}{|c|c|c|c|c|c|c|c|c|c|}
\hline \multirow{2}{*}{$x$} & \multirow{2}{*}{$y$} & $\left|u-U_{N-Z M M}\right|$ & \multicolumn{2}{|c|}{$\left|u-U_{P-Z A D M}\right|$} & $\left|u-U_{4(A D M)}\right|$ & \multicolumn{2}{|c|}{$\left|u-U_{8}(A D M)\right|$} & \multicolumn{2}{|c|}{$u-U_{12(A D M)}$} \\
\hline & & imag & & imag & imag & real & imag & real & imag \\
\hline 0.1 & $\overline{0.1}$ & $4.8 \mathrm{E}-05 \quad 1.3 \mathrm{E}-05$ & $6.5 \mathrm{E}-05$ & $1.3 \mathrm{E}-05$ & $1.4 \mathrm{E}-07 \quad 8.1 \mathrm{E}-07$ & $2.9 \mathrm{E}-11$ & $2.7 \mathrm{E}-10$ & 0 & 0 \\
\hline 0.2 & 0.2 & $9.7 \mathrm{E}-05 \quad 3.1 \mathrm{E}-05$ & $9.0 \mathrm{E}-05$ & $4.4 E-05$ & $2.2 \mathrm{E}-06 \quad 1.3 \mathrm{E}-05$ & $4.7 \mathrm{E}-10$ & $4.3 \mathrm{E}-09$ & 0 & 0 \\
\hline 0.3 & 0.3 & 7.3E-05 1.1E-04 & 3.7E-04 & $2.9 \mathrm{E}-04$ & $1.1 \mathrm{E}-05 \quad 6.6 \mathrm{E}-05$ & 2.3E-09 & $2.2 \mathrm{E}-08$ & 0 & 0 \\
\hline 0.4 & 0.4 & $3.9 \mathrm{E}-04 \quad 5.4 \mathrm{E}-04$ & $9.7 \mathrm{E}-04$ & 8.0E-04 & $3.5 \mathrm{E}-05 \quad 2.1 \mathrm{E}-04$ & $7.5 \mathrm{E}-09$ & $6.9 \mathrm{E}-08$ & 0 & 0 \\
\hline 0.5 & 0.5 & $4.2 \mathrm{E}-04 \quad 6.3 \mathrm{E}-05$ & $2.7 \mathrm{E}-03$ & $1.6 \mathrm{E}-03$ & $8.5 \mathrm{E}-05 \quad 5.1 \mathrm{E}-04$ & $1.7 \mathrm{E}-08$ & $1.7 \mathrm{E}-07$ & 0 & 0 \\
\hline 0.6 & 0.6 & $1.7 \mathrm{E}-03 \quad 4.4 \mathrm{E}-04$ & 4.6E-03 & $4.0 \mathrm{E}-03$ & $1.8 \mathrm{E}-04 \quad 1.1 \mathrm{E}-03$ & $3.7 \mathrm{E}-08$ & $3.6 \mathrm{E}-07$ & 0 & 0 \\
\hline 0.7 & 0.7 & $2.6 \mathrm{E}-03 \quad 5.4 \mathrm{E}-04$ & $4.4 \mathrm{E}-03$ & $6.2 \mathrm{E}-03$ & $3.3 \mathrm{E}-04 \quad 2.0 \mathrm{E}-03$ & $6.0 \mathrm{E}-08$ & $6.6 \mathrm{E}-07$ & 0 & 0 \\
\hline 0.8 & 0.8 & 8.1E-04 $5.2 \mathrm{E}-04$ & $3.6 \mathrm{E}-03$ & $4.9 \mathrm{E}-03$ & $5.6 \mathrm{E}-04 \quad 3.3 \mathrm{E}-03$ & $1.2 \mathrm{E}-07$ & $1.1 \mathrm{E}-06$ & 0 & 0 \\
\hline 0.9 & 0.9 & $7.0 \mathrm{E}-04 \quad 4.1 \mathrm{E}-04$ & $1.5 \mathrm{E}-03$ & $2.2 \mathrm{E}-03$ & $9.0 \mathrm{E}-04 \quad 5.3 \mathrm{E}-03$ & $2.1 \mathrm{E}-07$ & $1.9 \mathrm{E}-06$ & 0 & 0 \\
\hline \multicolumn{2}{|c|}{ CPUtime } & $229.13 s[13]$ & \multicolumn{2}{|c|}{$71.25 s[13]$} & $0.015 \mathrm{~s}$ & \multicolumn{2}{|c|}{$0.016 \mathrm{~s}$} & \multicolumn{2}{|c|}{$0.031 \mathrm{~s}$} \\
\hline
\end{tabular}




\section{J.Thi-Qar Sci.}
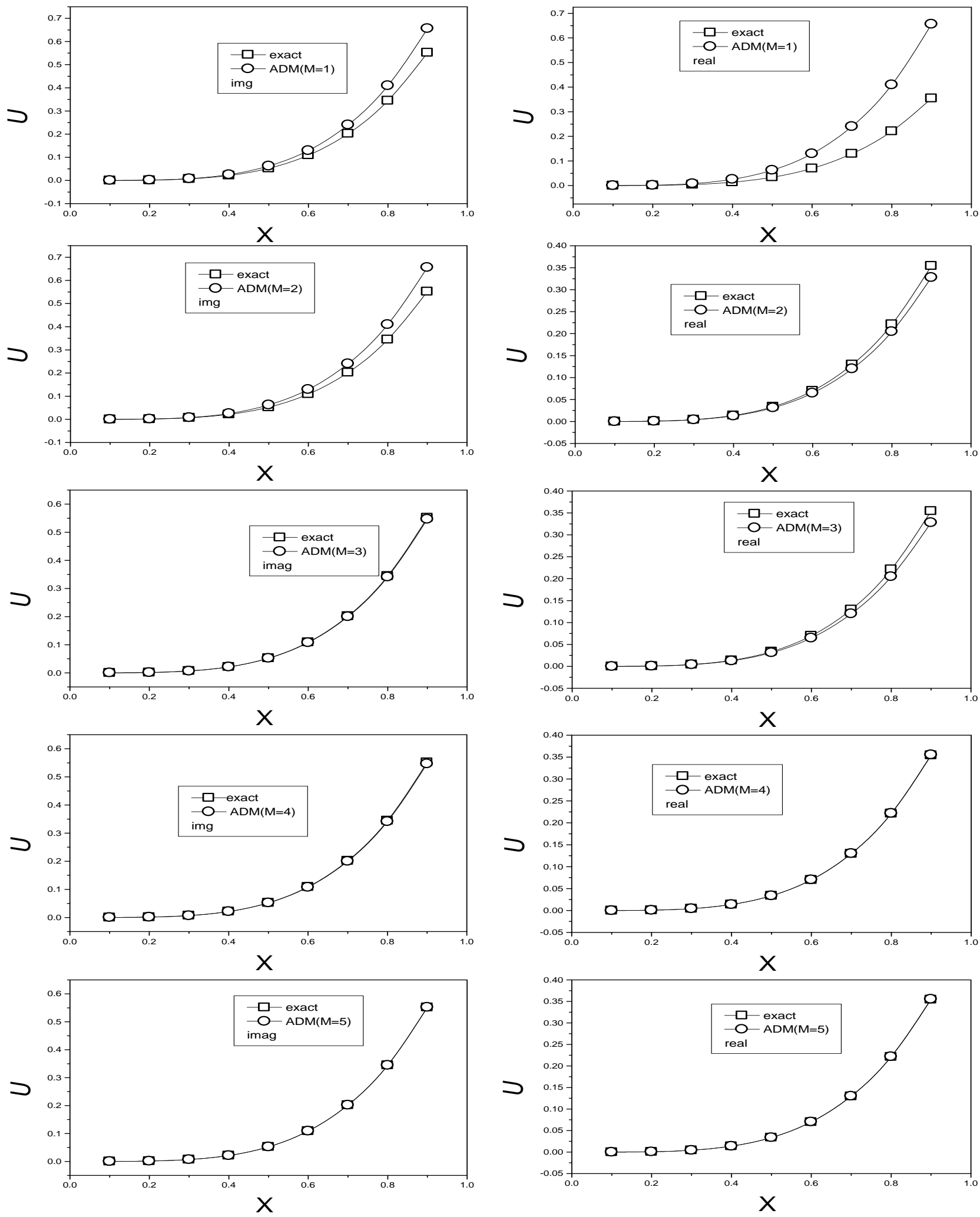

Figure 1. Numerical comparison between exact solution and ADM at the diagonal 


\section{J.Thi-Qar Sci.}
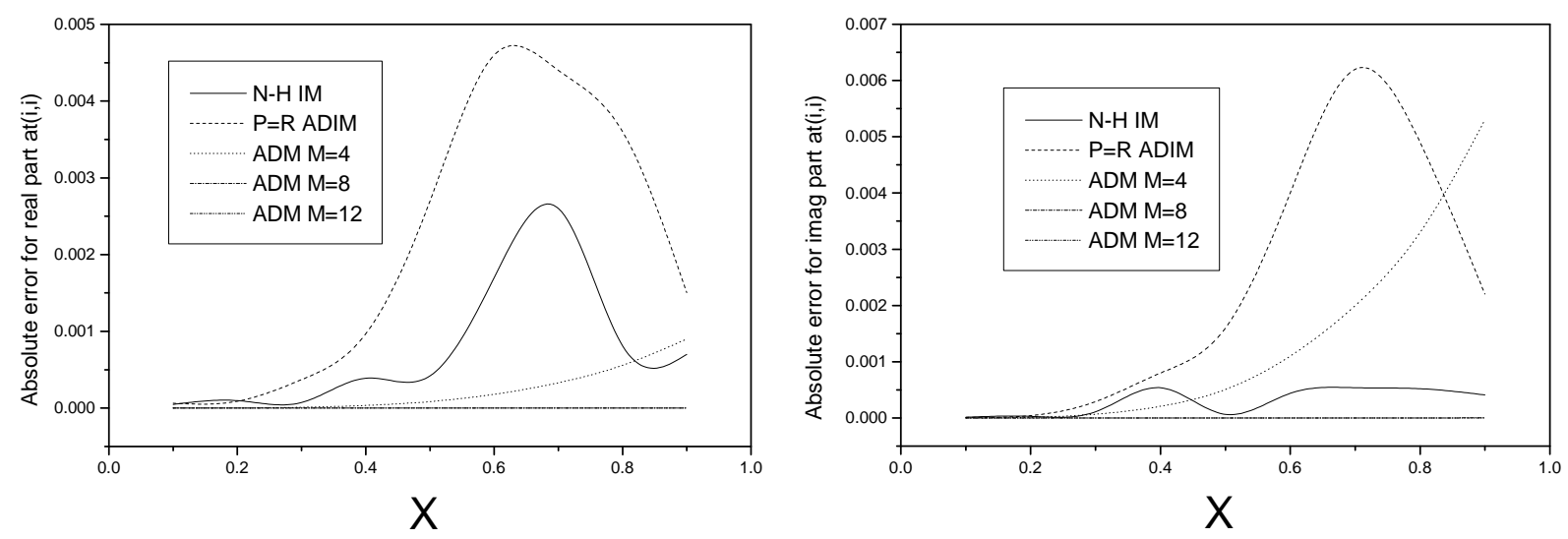

Figure 2. Absolute error comparison between the ADM and the other methods

\section{$\underline{\text { Convergence analysis }}$}

Convergence of ADM has been discussed by many researchers for different problems $[10,5]$. Here, we introduce a simple convergence analysis to the two-dimensional time dependent Schrödinger equation depending on convergence of the sequence $\left\{u_{k}\right\}$.

To demonstrate the convergence of the sequence $\left\{u_{k}\right\}$, we consider the series $S=\sum_{k=0}^{\infty}\left(u_{k+1}-u_{k}\right)$. The Nth partial sum $S_{N}=\sum_{k=0}^{N}\left(u_{k+1}-u_{k}\right)$ has the simple form $S_{N}=u_{N+1}-u_{0}$. We wish to show that the sequence of functions that defined by (10) converges uniformly to a function $u(x, y, t)$ for $0<t<T$.

Definition [12]: The series converges uniformly if the sequence of partial sum converges uniformly.

According to this definition, ADM is convergent if verifying the following theorem:

Theorem: The solution series of ADM applied to the TDSE with initial condition will converge uniformly if the scalar series $\sum_{k=0}^{\infty}\left\|u_{k+1}-u_{k}\right\|$ converges uniformly.

Proof: From the recurrence relation (10), we have

$$
u_{k+1}-u_{k}=\int_{0}^{t} L\left(u_{k}-u_{k-1}\right) g(\tau) d \tau, k \geq 1
$$

And thus $\left\|u_{k+1}-u_{k}\right\| \leq \int_{0}^{t}\left\|L\left(u_{k}-u_{k-1}\right)\right\|\|g(\tau)\| d \tau \quad, k \geq 1$

Here, for simplicity we assume that $L=L_{x x}+L_{y y}+\psi$. 


$$
\begin{aligned}
& \text { Let } \quad C=\max \mid L\|g(t)\| \quad \text { for } \quad 0 \leq t \leq T \text {. } \quad \text { Then } \quad \text { (13) } \quad \text {..(14) } \\
& \left\|u_{k+1}-u_{k}\right\| \leq C \int_{0}^{t}\left\|u_{k}-u_{k-1}\right\| d \tau
\end{aligned}
$$

Since $\left\|u_{1}-u_{0}\right\| \leq \int_{0}^{t}\left\|u_{0}\right\|\|g(\tau)\| d \tau \leq C\left\|C_{1}\right\| t \quad$, we obtain

$$
\left\|u_{k+1}-u_{k}\right\| \leq\left\|C_{1}\right\| \frac{(C t)^{k+1}}{(k+1) !} \quad, k=0,1,2, \ldots
$$

The uniform convergence of the exponential series on any closed finite interval $[0, T]$, where $T$ is a fixed positive real number, ensures the uniform convergence of $\sum_{k=0}^{\infty}\left\|u_{k+1}-u_{k}\right\|$ and; therefore, the sequence $\left\{u_{k}\right\}$ is converging.

\section{$\underline{\text { Conclusions }}$}

The ADM was used for finding exact and approximate solutions of the two-dimensional Schrödinger equation successfully. In this numerical study the efficiency of ADM was demonstrated. A decomposition method avoids the disadvantages that appear by using N-Him and P-R RADIM such as extensive computational and tedious workloads. In addition, it is more efficient and yields easier calculations. Advantages of ADM are motivated to interest for improving and extending the application of this method for solving nonlinear fluid flow problems in the future works.

\section{$\underline{\text { References }}$}

[1]- Adomian G. (1988)" A review of the decomposition method in applied mathematics", Math. Anal. Appl. 135, 501-544.

[2]- Adomian G. (1994)"Solution of nonlinear evolution equations" Math. Comput. Modelling, 20 ,1-2.

[3]- Adomian G. (1994)" Solving frontier problems of physics: the decomposition method" Kluwer, Boston.

[4]- Chen W.,and Lu Z. (2004)" An algorithm for Adomian decomposition method", Appl. Math. Comput. $159,221-235$.

[5]- Cherruault Y. and Adomian G. (1993)" Decompostion methods: A new proof of convergence" Comput. Modelling, 18, 103-106.

[6]- Hajj F.,Y., (1985)" Solution of the Schrödinger equation in two and three dimension" J. Phys.B Mol.Phys., 18, 1-11

[7]- Huang W.,Xu C.,Chu S.T., and Chaudhuri S.K. (1992)" The finite-difference vector beam propagation method: Analysis and assessment", J. of Light wave Tech. ,10(3),295-304.

[8]- Michell A.R. and Griffiths D.F. (1980)" The finite difference analysis methods in partial differential equations"Wiley,New York.

[9]-Momani S.(2007)" A decomposition method for solving unsteady convection- diffusion problems" Turk J. Math. 31,1-10

[10]-Mustafa I. (2005)" Decompostion method for solving parabolic equations in finite domains" J. of Zhejian Uni. Sci., 6A(10) ,1058-1064. 


\section{J.Thi-Qar Sci.}

[11]-Noye B.J. and Hayman K.J. (1993)" Implicit two-level finite differences methods for the twodimensional diffusion equation"Int. J. Comput. Math., 48 , 219-228.

[12]-Rubin W. (1964)" Principle of Mathematical Analysis", Mc Graw/Hill.

[13]- Subasi M. (2002)" On the finite-difference schemes for numerical solution of two dimensional Schrödinger equation" Int. Numer. Methods Partial Differ. Eq., 18,752-758.

[14]- Wazwaz A. M. (2006)"Exact solutions for the fourth order nonlinear Schrodinger equations with cubic and power law nonlinearities" Math. and Comput.Modeling 43, 802-808.

\section{طريقة تحليل ادومين لحَلّ معادلةِ شرودنكرثنائية البعد}

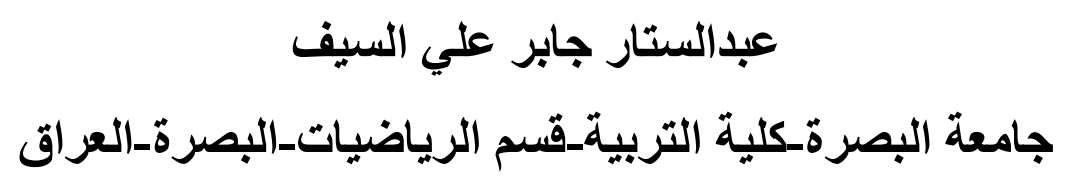

الخلاصة

هنا تم تطبيق طريقة تحليل ادومين( Adomian) لتقريبِ حَلِّ معادلةِ شرودنكر(Schrödinger )ثنائية البعد،

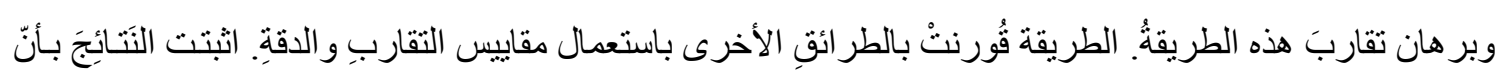

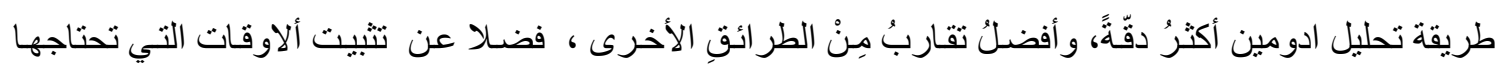

وحدة المعالجة المركزيةِ لحل هذه المسألة. 